Issued by Sandia National Laboratories, operated for the United States Department of Energy by Sandia Corporation.

NOTICE: This report was prepared as an account of work sponsored by an agency of the United States Government. Neither the United States Government nor any agency thereof, nor any of their employees, nor any of their contractors, subcontractors, or their employees, makes any warranty, express or implied, or assumes any legal liability or responsibility for the accuracy, completeness, or usefulness of any information, apparatus, product, or process disclosed, or represents that its use would not infringe privately owned rights. Reference herein to any specific commercial product, process, or service ty trade name, trademark, manufacturer, or otherwise, does not necessarily constitute or imply its endorsement, recommendation, or favoring by the United States Government, any agency thereof or any of their contractors or subcontractors. The views and opinions expressed herein do not necessarily state or reflect those of the United States Government, any agency thereof or any of their contractors.

Printed in the United States of America. This report has been reproduced directly from the best available copy.

Available to DOE and DOE contractors from

Office of Scientific and Technical Information

PO Box 62

Oak Ridge, TN 37831

Prices available from (615) 576-8401, FTS 626-8401

Available to the public from

National Technical Information Service

US Department of Commerce

5285 Port Royal Rd

Springfield, VA 22161

NTIS price codes

Printed copy: A03

Microfiche copy: A01 


\title{
Preliminary Evaluation of Hermetic JT/LJT/R\&P Connector Socket Contact Design
}

\author{
Johnny R. F. Baca \\ Connectors Division \\ Sandia National Laboratories \\ Albuquerque, NM 87185
}

\begin{abstract}
This report presents a precursory examination of a number of issues pertaining to socket contacts in hermetic connectors. The principal issues addressed are highcontact resistance and contact chatter (circuit discontinuities). Efforts examining the characteristics of the existing socket contact design, the possibility of connector/ contact rework, quick-fix solutions, and contact redesigns are summarized.
\end{abstract}




\section{Preliminary Evaluation of Hermetic JT/LJT/R\&P Connector Socket Contact Design}

\section{Introduction}

This report is a verbatim reproduction of an information-sharing memo written by J. R. F. Baca (the author of this SAND document) to R. D. Holt, SNL Org. 2551. The memo is dated December 11, 1990; its subject: High-Contact Resistance and Contact Chatter in JT, LJT, R\&P Hermetic Connectors.

My reason for writing this information-sharing memo was prompted by a memo I had received from R. D. Holt, dated November 19, 1990, subject: Meeting Minutes from the LAC Contact Resistance Meeting, Novernber 8, at SNL Albuquerque. It was very apparent that we were both trying to solve the same problem, even though our components were different and, in fact, they are used for different applications.

As a means of averting further duplication of effort, my memo-the focus of this SAND report-was prepared to identify concerns, ideas, plans, and studies undertaken. This report documents the evaluation studies that have been made, and my hope is that it will serve also as a history/reference source. My evaluations are inconclusive, and do not necessarily represent the position of either Department 2550 or Division 2551. My memo of December 11, 1990, follows. 


\section{Information-Sharing Memo}

Allied Signal, KCP, has been experiencing high-contact resistance $(C R)$ and contact chatter in hermetic connectors. It was brought to my attention this past summer.

It is obvious that your LAC connector and my hermetic connectors are experiencing the same problems and understandatly so, since they use essentially the same contact design. Unfortunately, we have been duplicating effort to solve the same problem.

I will attempt to address what I consider to be the two main issues:

1. What do we do with connectors in the field/stockpile and in $\mathrm{KCD} / \mathrm{GEND}$ stores?

a) This requires immediate attention to provide direction to connector users. He basically have three choices:

1) Use the connectors "as is".

2) Rework the connectors.

3) Scrap and replace all hermetic (and LAC) connectors in the field/stockpile and in KCD,GEND stores.

2. Design a better/superior contact. This is clear-cut and easy to do.

I. Present Contact Desion - Number 1 Contributor of Contact Chatter and CR Problems

Based on my evaluation of the contact/spring design, I surmise that the main function of the spring dimple is to deflect the mating pin contact onto the socket contact wall to provide a circuit path (Fig. 1).

Main Problem - The spring member itself does not always make positive contact with the socket contact body (Fig. 1B, 2B).

a) The spring member itself is of a split-ring design. It is susceptible to expansion and contraction at temperature extremes; thereby affecting $C R$ and potentially circuit continuity (Fig. 2A, 2E). 
b) Contact/spring tolerances are such that the fit between the two can range from .0048 interference to .0016 clearance for Size 22 contacts, .0025 interference to .0039 clearance for size 20 contacts, and .004 interference to .003 clearance for size 16 contacts (Fig. 2A, 2B).

Under loose conditions, tolerances also allow the spring member axial/linear movement of .003 to .017 for size 22 contacts, .002 to .016 for size 20 contacts, and .002 to .016 for size 16 rontacts; total rotational travel of $37^{\circ}$ maximum for size 22 contacts, $26^{\circ}$ maximum for size 20 contacts, and $21^{\circ}$ maximum for size 16 contacts (Fig. 3A).

c) Physically handling individual socket contact assemblies revealed the looseness of the spring member; i.e., axial and rotational movement can be seen and felt (Fig. 3A).

d) Rattling of the spring members can be heard by shaking a hermetic connector with size 20 contacts next to your ear. Rattling of the spring members is distinct from the rattle of the captive corrugated strip spring used for insert retention.

Rattling of the spring members is not audible in hermetic connectors using size 22 contacts (has tighter tolerances, as indicated).

e) Loose fitting spring members in a connector are readily detected under magnification by lightly/partially inserting an undersized pin contact or facsimile into the contact (dimple area). Then by gently rotating and pushing/pulling on the pin contact or facsimile, one can see the movement (Fia. 3B).

f) Slight movement in a connector can cause loose fitting spring members to shift; thereby affecting $\mathrm{CR}$ and potentially circuit continuity.

NOTES :

1. The subject problems are prevalent in connectors using size 20 contacts. Tolerances indicate that size 20 contacts/spring members have the greatest chance for loose spring members.

2. I suspect this problem did not surface earlier because test adapters used "loose" crimp-type contacts which were able to self-center in the socket contact. Today's rigid-insert connectors are not so forgiving. 


\section{Present Contact Design - Number 2 Contributor of CR}

\section{Problems.}

A graphic and dimensional study of the present design revealed an inherent tendency for the mating pin contact to tear/abrade the plating off the spring dimple.

a) The aggressive $60^{\circ}$ deflective angle (Size 20 contact), on the spring dimple, from the axis is not conducive to minimal wear sliding action between two surfaces. The angle indicates to me that its intent is to guide/push the pin contact onto the socket contact wall.

b) The mating pin contact is rarely spherical tipped (Fig. 4). Fabrication drawings allow a maximum diameter flat at the tip of 0.010 for size 22 contacts, 0.016 for size 20 contacts, and 0.031 for Size 16 contacts. The spherical radius/flat intersect provides an edge that helps promote "tearing" of the plating when the pin contact entry angle is not at true position but towards the dimple.

NOTE: Recent scrutiny of pin contact connectors, both incoming and in stores at $\mathrm{KCP}$, has revealed pin contacts with diameter flats significantly in excess of the maximum allowed.

c) Premature and excessive plating wear is inevitable due to high forces generated at the spring dimple/pin contact interface point. The pin contact will resist deflecting onto the socket contact wall and the spring dimple tine is subjected to a downward insertion force at roughly $30^{\circ}-45^{\circ}$ from the axis (Fig. 4). The insertion force cxeates a slight tendency in the spring dimple tine to want to bend inward.

NOTES :

Viewing sizes 22 and 20 socket contacts in various types of hermetic connectors under magnification revealed discoloration in the dimple area where mating occurs. Reddish-brown, green and black are colors seen in abraded areas. Slivers of gold plating were also observed clinging to the dimple by a micro-hair. 
Discoloration in the socket contacts used in standard JT, IJT and R\&P connectors was discovered recently. The conclusion was that different color copper oxides were present due to little or no nickel/gold plating. The black color was probably due to residual plating solution corrosion build-up accelerated by the lack of plating/plating thickness.

Presently, KCP cleans socket contacts in hermetic connectors with Tri-chlor and alcohol, then blow-dry, bake and dry.

III. Characteristics of Existing Design - Summarized.

a) Low $C R$ can be achieved if the mating pin contact is secure against the socket contact wall.

b) Low $C R$ can be achieved if the mating pin contact is secure against the spring dimple if the spring member itself is attached to the socket contact body by means of an interference fit and the dimple is devoid of corrosion/foreign material.

c) Absence of contact chatter can be achieved if conditions $a$ and $b$ are present.

d) The dimple's shallow deflective angle promotes premature and excessive plating wear.

e) Loose fitting spring member:

1) Spring member is susceptible to contraction and expansion at temperature extremes.

2) Spring membar is susceptible to resonance/oscillation.

f) The design concept is not conducive to mating with a rigid insert-rigid contact connector.

IV. Rework of Existing Hermetic (and LAC) Connectors.

There is no way to rework the spring member dimple and its design intent. I do believe, however, that the spring member/socket contact "press fit" can be reworked.

My thoughts are to press fit a sleeve over the spring member to achieve the intended press fit and positive contact between the spring member and socket contact body.

Department 1830 will recommend a material that can be pressed on, as opposed to shrunk on, at ambient conditions with no significant expansion and contraction at temperature extremes. 
A) Tools Required (Fig. 5)

1) Jig Bore; Drill Press; Hand Drill, etc.

2) Vacuum Chip Evacuator (through the center of or external to the cutter).

3) Coring Template (Fig. 6).

4) Straight or Stepped Core Drill (Carbide or High-Speed).

B) Procedure

1) Install Template

2) Core out the Contact Protective-Guide Web.

3) Remove Template.

4) Apply Air Pressure to Cored Holes to clean out.

5) Install sleeve (Fig. 7, 8B).

Sleeve installation can be done using the same type of tool used by BCO to install the spring member, except for a redesign of the guideplunger. The dimple will be used for indexing during installation.

I am currently evaluating the feasibility of rework by subjecting hermetic connectors using size 22 and size 20 contacts to the following:

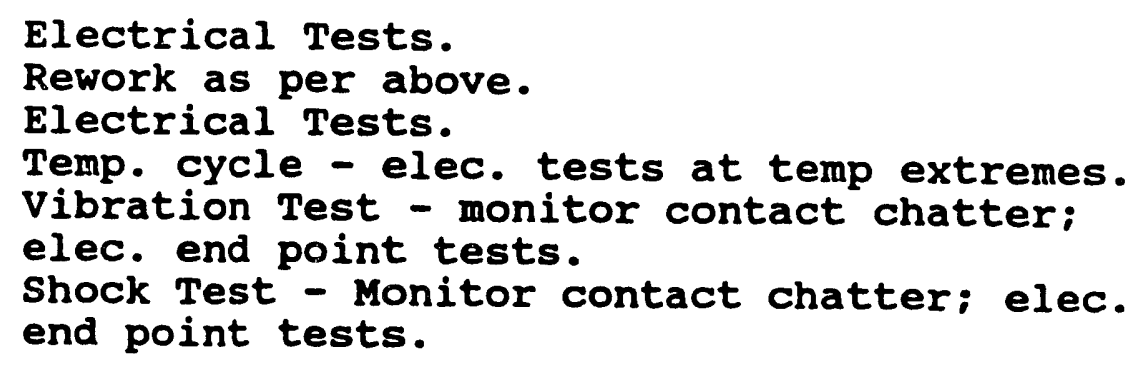

If rework proves successful and acceptable/worthwhile, I will prepare formal procedures.

NOTE: Rework can take place in a shop environment or "in the field."

\section{v. ouick-Fix of Hermetic (and IAC) connectors in production.}

Here again, there is no way to rework the spring member dimple and its design intent. However, a harder plating can be used and the spring member/socket contact "press fit" can be improved. 
a) Plate the spring member per BCO Spec 9-5559 (hard gold plate-Autronex $C)$. The trade name is selRex Corp., Nutley, NJ.

- Purity: The gold strike shall be $99.7 \%$ gold minimum. The gold plate shall be $99.5 \%$ minimum.

- Hardness: The hardness of the gold plate shall be 201 knoop minimum. The hardness of the gold strike shall be 129 knoop maximum.

b1) Use existing spring member design except seam weld (laser or E-beam) the split joint and ensure tolerances will allow a maximum clearance of .000 between the spring member and the contact body (Fig. 9A).

b2) Use existing spring member design, except press fit or shrink fit a sleeve similar to the rework sleeve in Fig. 7. The sleeve will be installed right after installation of the spring member and prior to installing the insert (Fig. 9B).

\section{Quick-Fix: Required Changes summarized}

1) Hard gold plating - a "minor" change in plating processes is required.

2) bl: Dimensional/tolerance control change is required.

Welding operation required.

3) b2: Sleeve fabrication is required.

sleeve installation is required.

VI. Redesign of the contact.

A redesign of the contact is in order and multiple tines are requisite.

Examples of the multiple tine designs used in standard JT, LTT and R\&P connectors are illustrated in Figures $11 \mathrm{~A}$ and 11B. The contact itself is made from BeCu wire/rod on an automatic screw machine. The wire/rod is rotated into the cutting tool where the ID is drilled, slots cut, redrilled to remove burrs and tines crimped. Then the remainder of the machining is done.

Note that the resultant tines are of a circular configuration. Circular tines by design would contact the mating pin contact at two points/lines at most if every element involved is at true position. 
Size 22 contacts have only two tines due to size limitations, as opposed to four tines used in sizes 20 and 16 contacts.

A protective hood is pressed over the contact to provide a barrier during the insert (insulator) molding operation. The hood opening also prevents damage by forced insertion of an oversized pin contact or test probe. The protectiveguide web in hermetic inserts serve the same purpose, except for acting as a barrier, which is not required in hermetics (Fig. 8A, 10C).

Recent TMS testing of standard connectors using 2 -tine and 4-tine contacts has produced positive results. Contact resistance and contact chatter tests were part of the TMS test plan. The positive test results support the use of 2tine and 4-tine contacts.

Three basic designs in the order of preference are:

1. The contact and tines are of one integral piece (Fig. 10A).

a) The contact/tine material would have to be compatible with the glass preform/bead.

b) The contact/tine material would have to retain its spring temper and resist oxidation under glass fuzing temperatures $\left(1800^{\circ}-1850^{\circ} \mathrm{F}\right)$.

c) A different type of glass might have to be used to attain the above.

Department 1830 is assisting in researching this possibility. I would eventually involve Department 1510 to provide a finite element analysis of the tine design.

NOTES :

1) The number of production processes, piece parts, and inspections would be reduced.

2) Fairly extensive tooling changes would be required.

3) Greatly improved longevity and reliability through simplicity and improved tine design.

2. The spring member and contact body joined through welding (Fig. 10B).

a) Resistance weld the spring member to the contact prior to the glass fuzing operation. After fuzing, plate the contacts and install the insert. 
b) The spring member would have to retain its spring temper and resist oxidation under glass fuzing temperatures $\left(1800^{\circ}-1850^{\circ} \mathrm{F}\right)$. Presently, BCO builds tines from BeCu, Inconel and 17-4 CRES.

Department 1830 is assisting in the material research. I would eventually involve Department 1510 to provide a finite element analysis of the tine design.

NOTES :

1) The number of production processes, piece parts and inspections remain about the same.

2) Minimal to moderate tooling changes would be required.

3) Improved longevity and reliability through welding and improved tine design.

The spring member and contact body could be joined by the vapor phase soldering process, as was done on the SA3511 connector (Fig. 10C). This operation would take place after the contact plating operation and prior to installing the insert. The main drawback is limited operation temperatures, particularly at the upper extremes, even if high-temp solder is used.

3. Press fit (or shrink fit) the spring member onto the contact body (Fig. 12).

With the objective of using existing processes, methods, materials, tooling, etc., wherever possible, and based on the IMS test results alluded to earlier, my design focus is on a 2 -tine spring member.

Two tines give me two points/lines of contact when the mating pin contact is "centered" (Fig. 13A). I can have as many as three points/lines of contact if the mating pin contact is off-center against the socket contact wall normal to the tines (Fig. 13B).

a) The present socket contact body can be used, except that two small "windows," $180^{\circ}$ apart, will be used instead of one large "window." 
b) The spring member will be stamped as presently done, except it will be laser or E-beam welded at the seam. It will be pressed on or shrunk on and will use the same axial retentioi. feature. The loosest fit will be .000 clearance in the pressedon condition. The tines will have a flat surface normal to the mating pin contact diarneter and a "large" radius/curve along the axis (Fig. 12).

Department 1510 will be involved in the finite element analysis of the tine design.

Manufacturing Changes summarized.

1. Contact body - machine two "windows," instead of one.

2. Spring member - stamp two dimples/tines, instead of one; weld the seam.

3. Contact assembly tool - redesign/modify the guideplunger.

NOTES :

1) The number of production processes, piece parts and inspections remain about the same.

2) Minimal tooling changes wovld be required.

3) Improved longevity and reliability through improved tine design and press/shrink fit.

Although BCO has been pressing spring members onto socket contact bodies for at least two decades, I must admit that I am not fond of pressing plated surfaces. The leading edges of the spring member will be chamfered ir rounded to facilitate installation and reduce plating tears.

VII. Conclusion.

Redesign of the contact is a long lead-time fix and should serve future applications well. I believe that reworl of existing connectors and the quick-fix of connectors currently in production are do-able, but whether either one is acceptable or desirable needs to be addressed. 


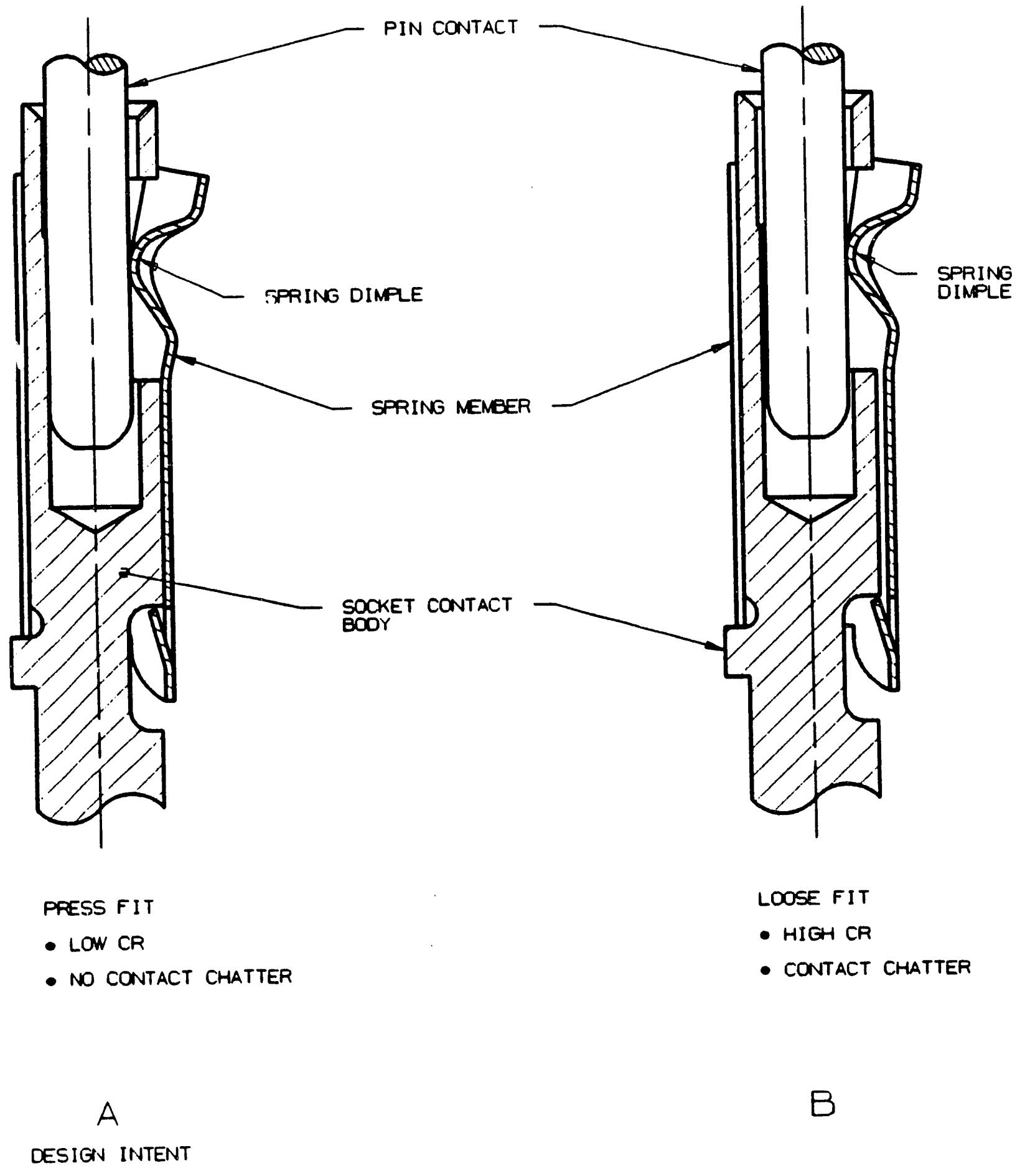

(SIZE 20 CONTACT)

FIG. I 

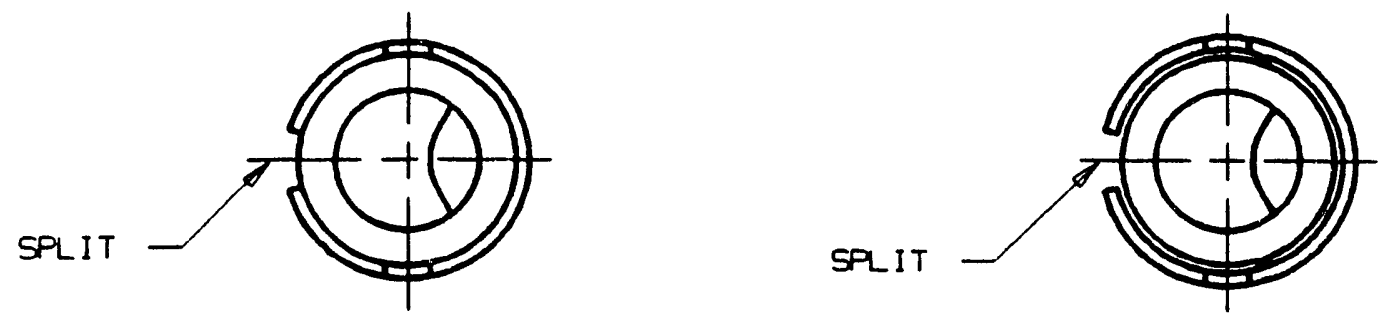

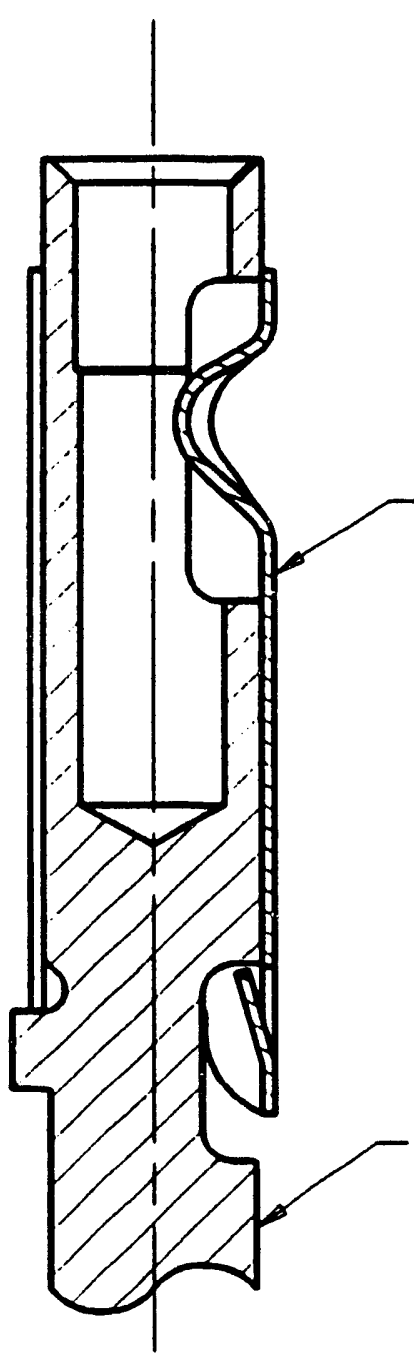

INTEPFERENCE FIT

A

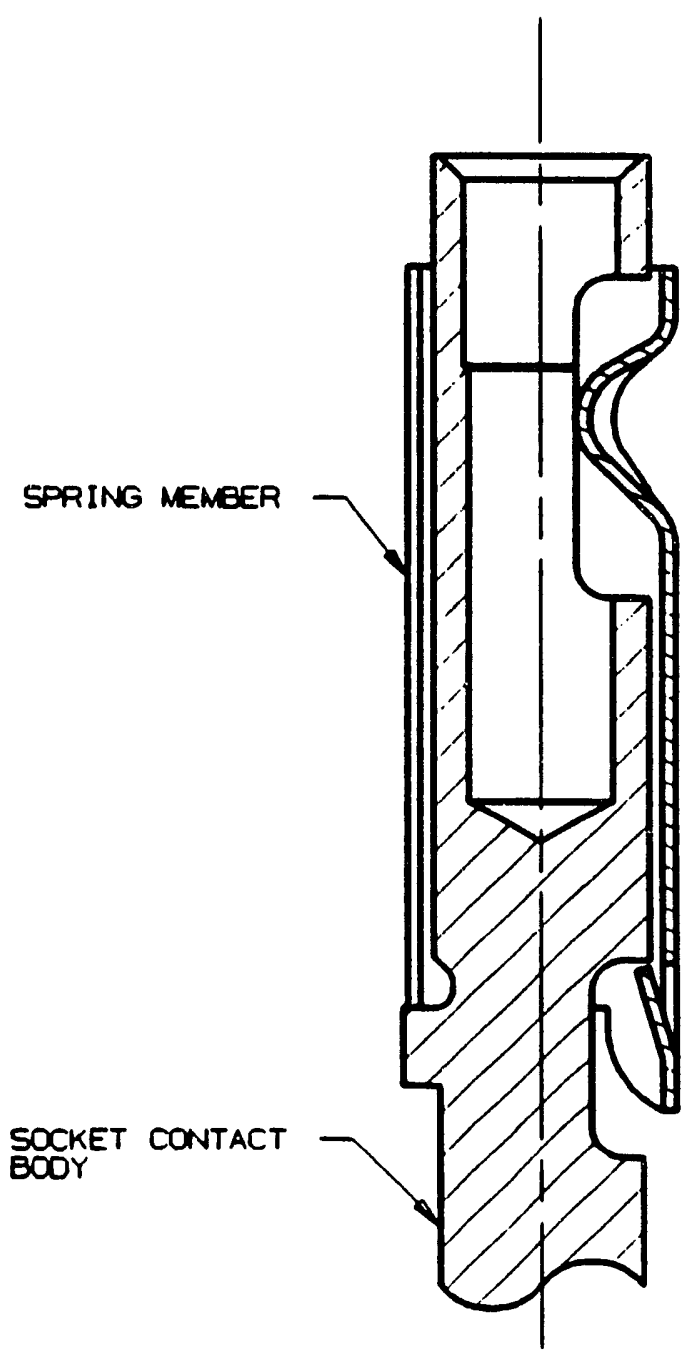

CleARANCE FIT

$B$

(SIZE 20 CONTACT)

FIG. 2 

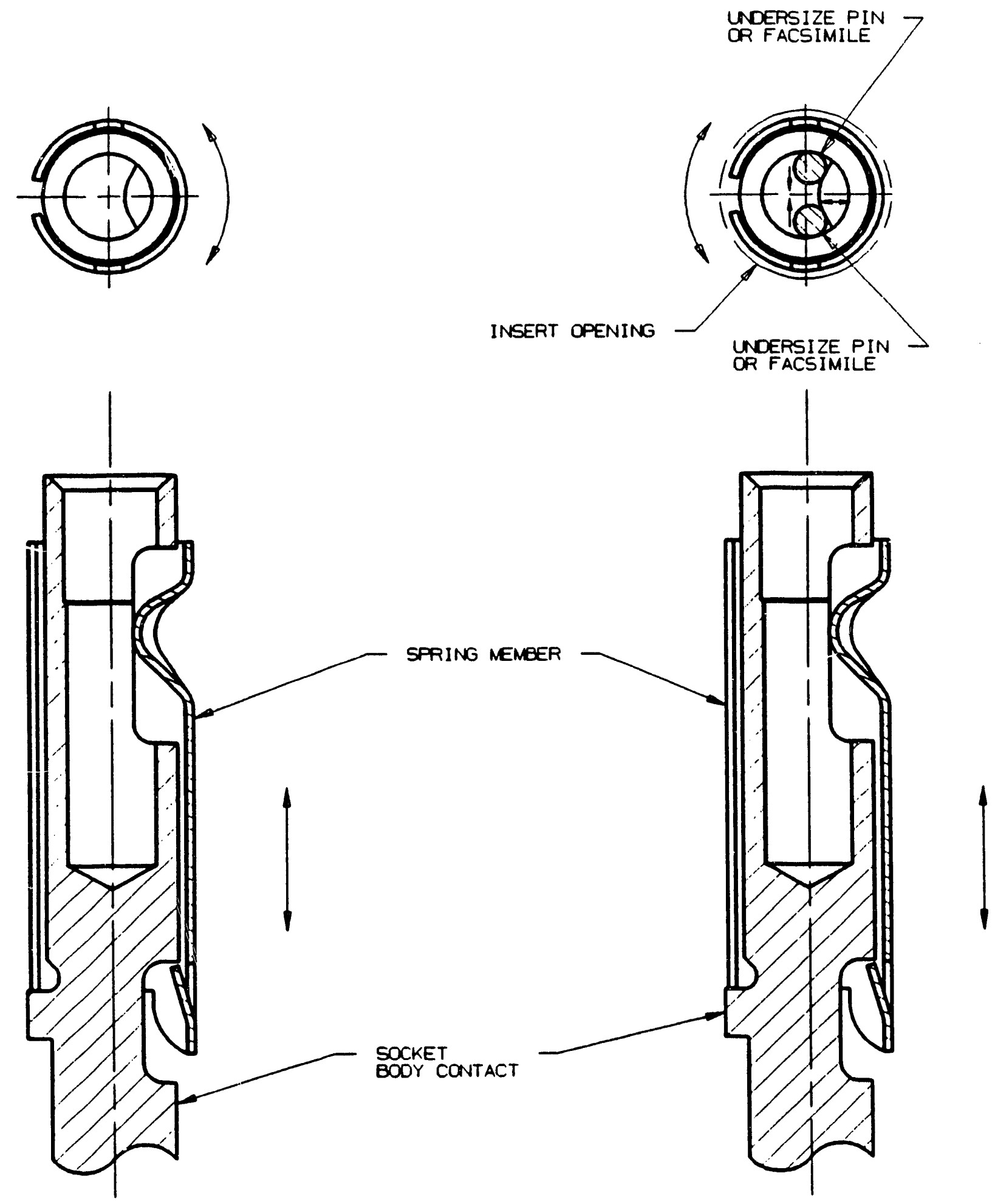

A

B

$$
\begin{gathered}
\text { (SIZE } 20 \text { CONTACT) } \\
\text { FIG. } 3
\end{gathered}
$$




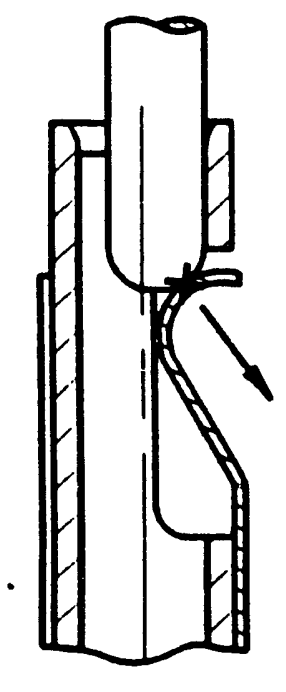

SIZE 22

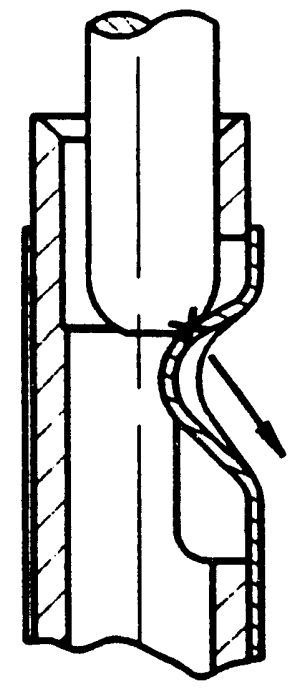

SIZE 20

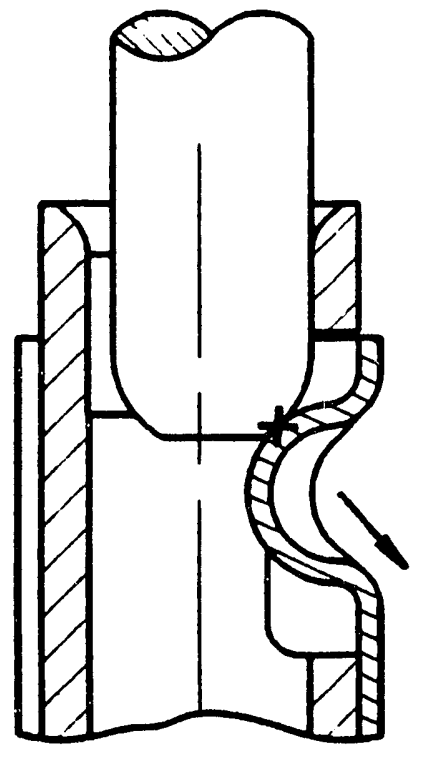

SIIE 16

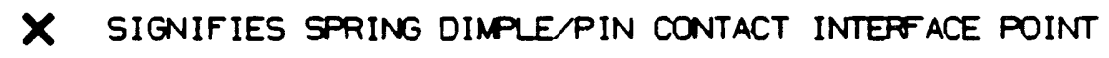

$\rightarrow$ SIGNIFIES INSERTION FORCE VECTOR

$$
\text { FIG. } 4
$$




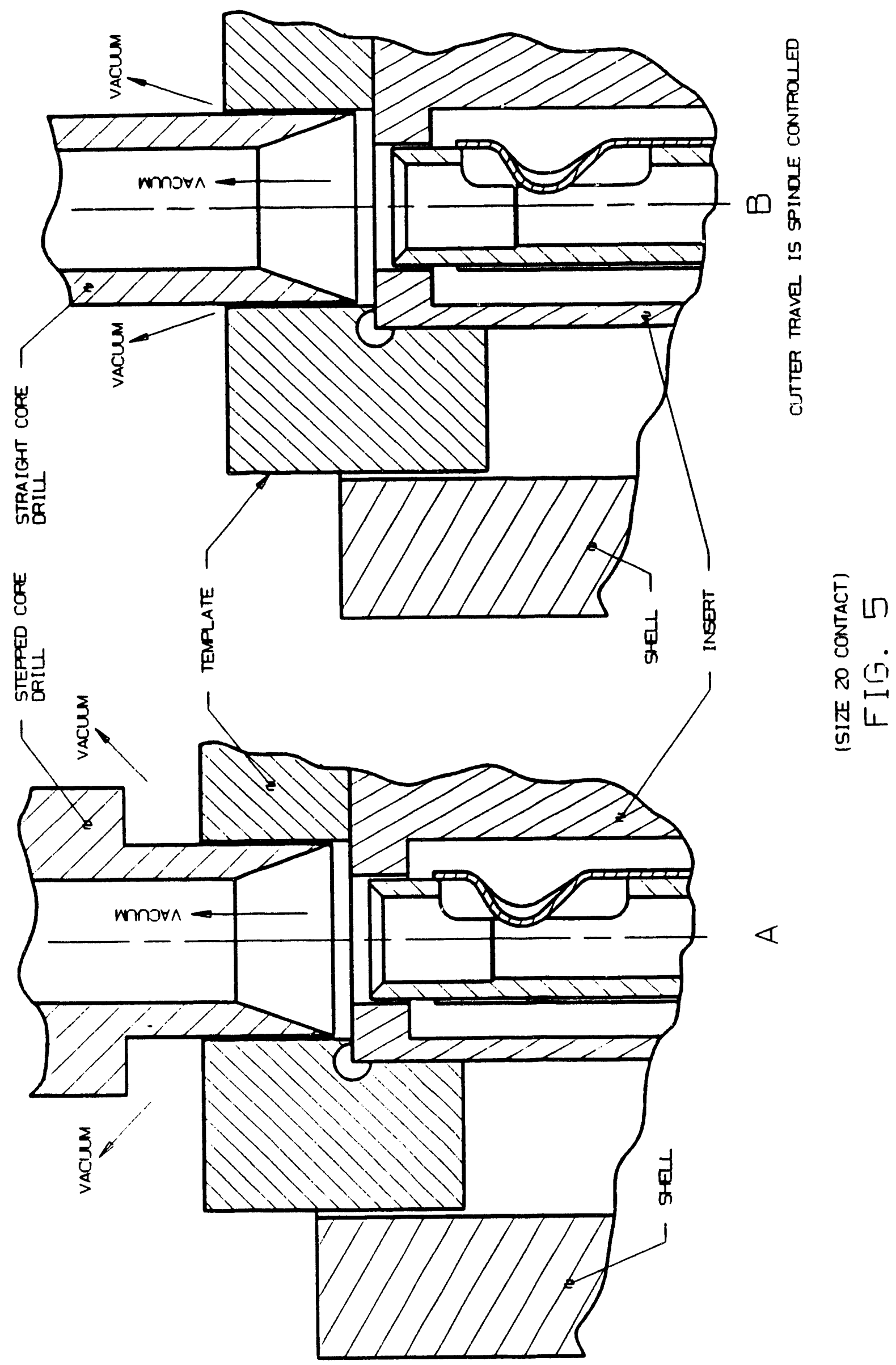



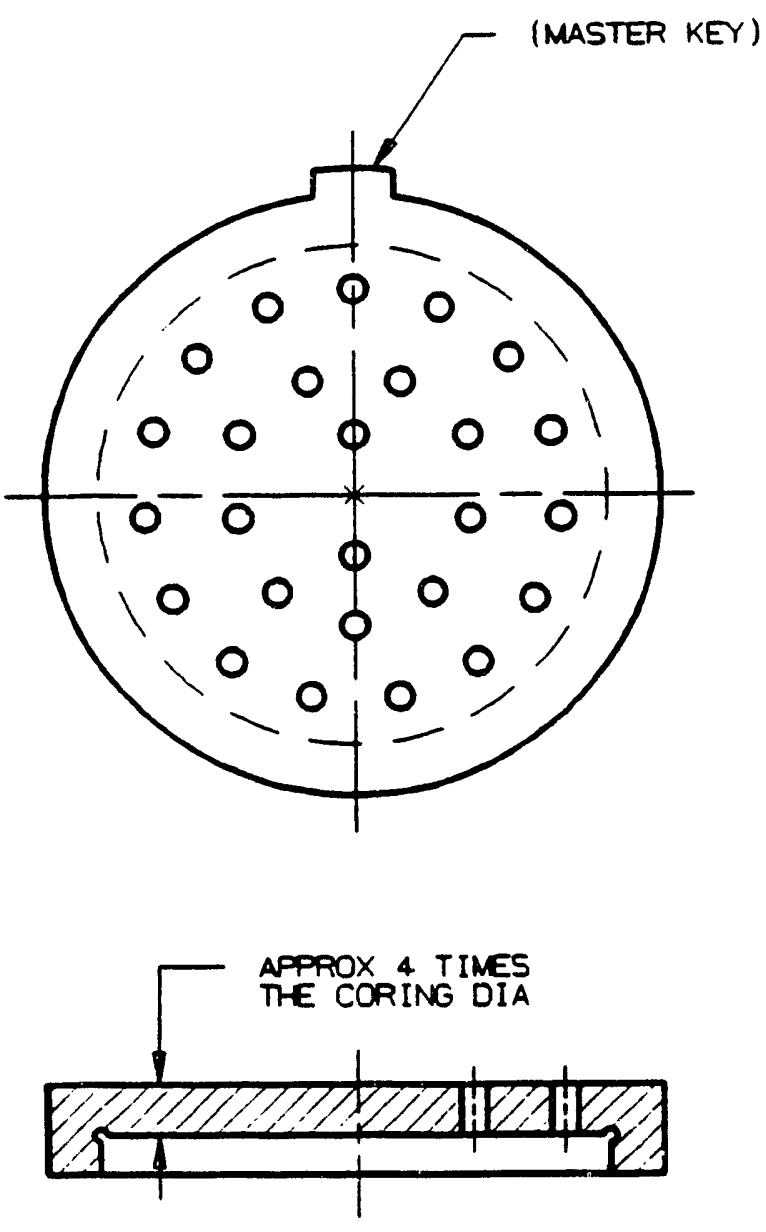
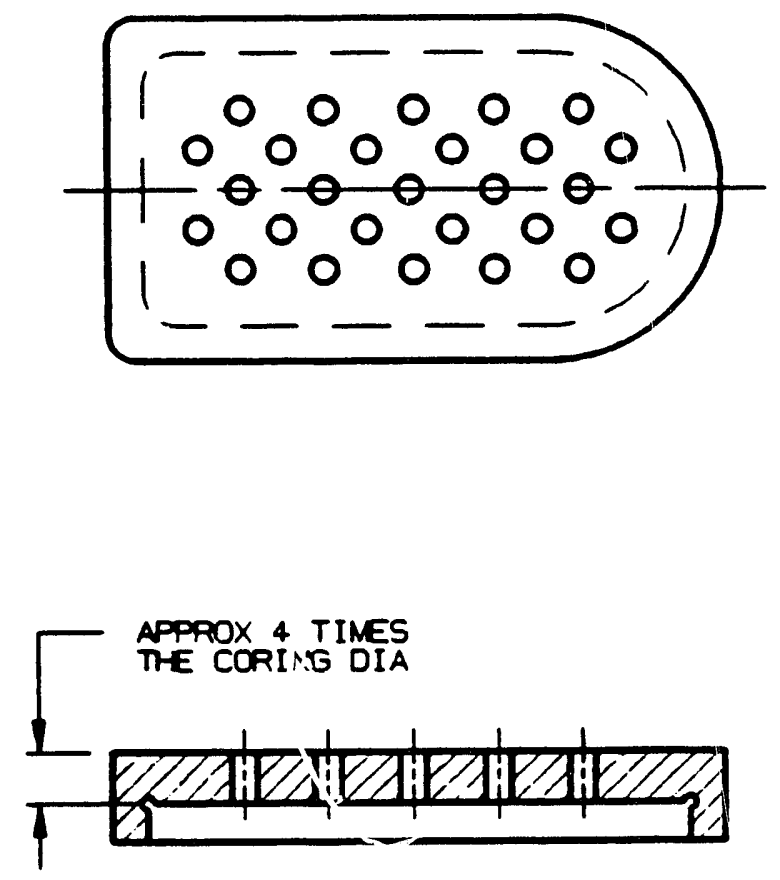
NOTE: TEMPLATE ANO HOE PATTEPN AFE "TIED" TO THE SAME DATUNS
USED IN FABRICATING THE CONECTOR "

MATL: CRES OR FEAT-TREATED TOOL STEE.

FIG. 6 

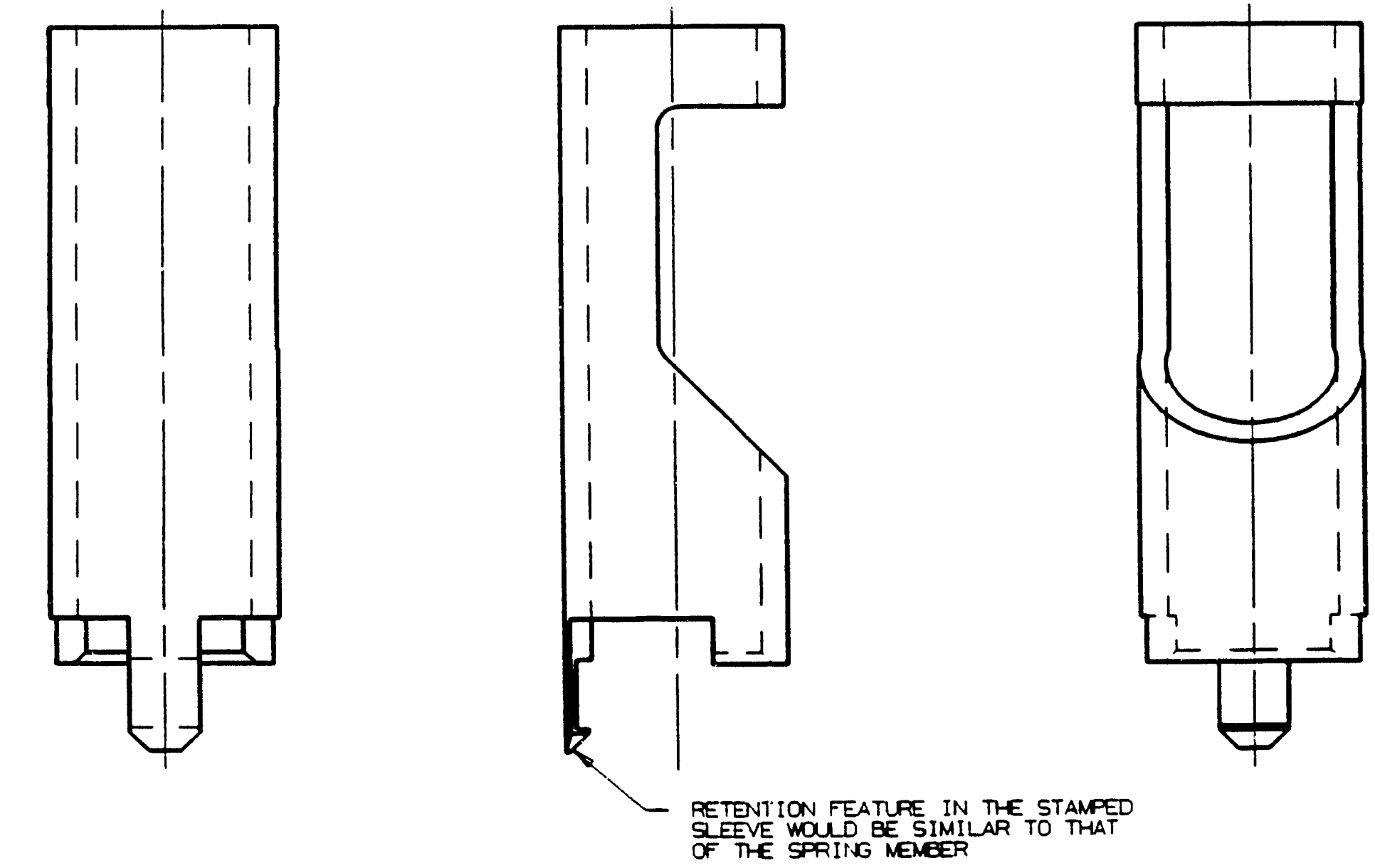

MACHINED SLEEVE

(STAMPED SLEEVE: LASER OR E-BEAM WELDED AT THE SEAM)

FIG. 7 


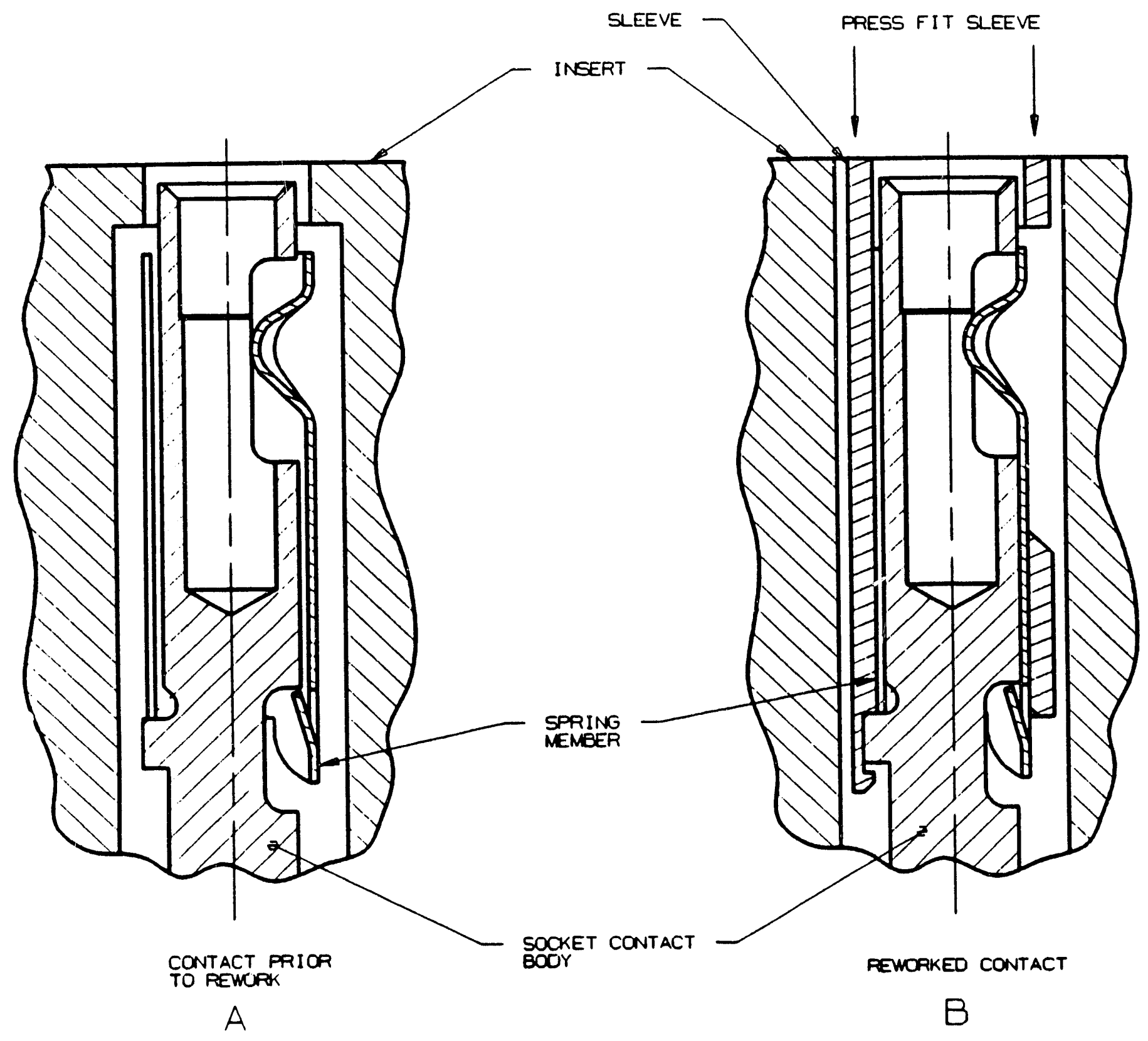

(SIZE 20 CONTACT)
FIG. 8 

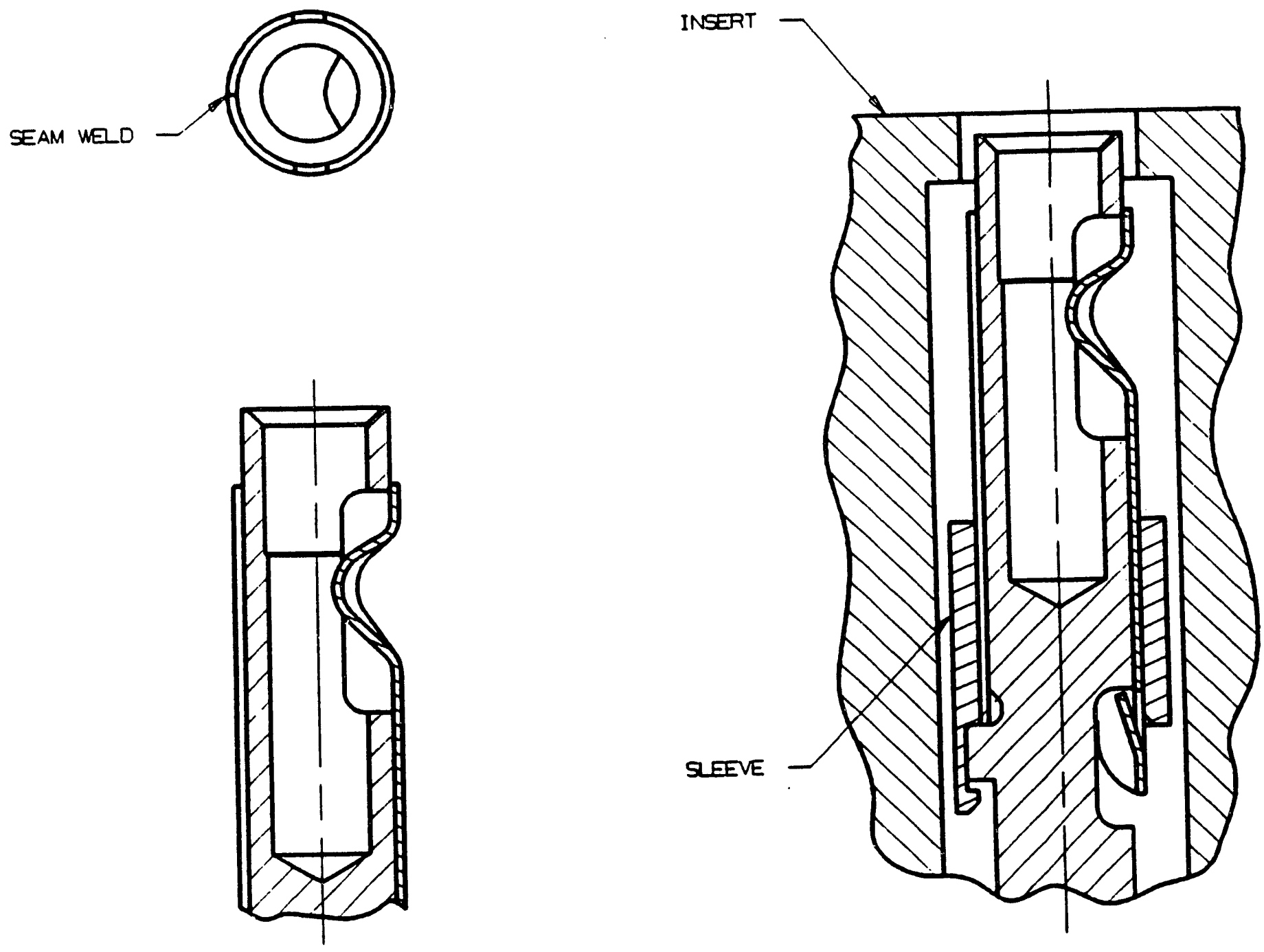

PRESS FIT OR SRINK FIT SLEVE

PRESS FIT

A

(SIZE 20 CONTACT)

B

FIG. 9 


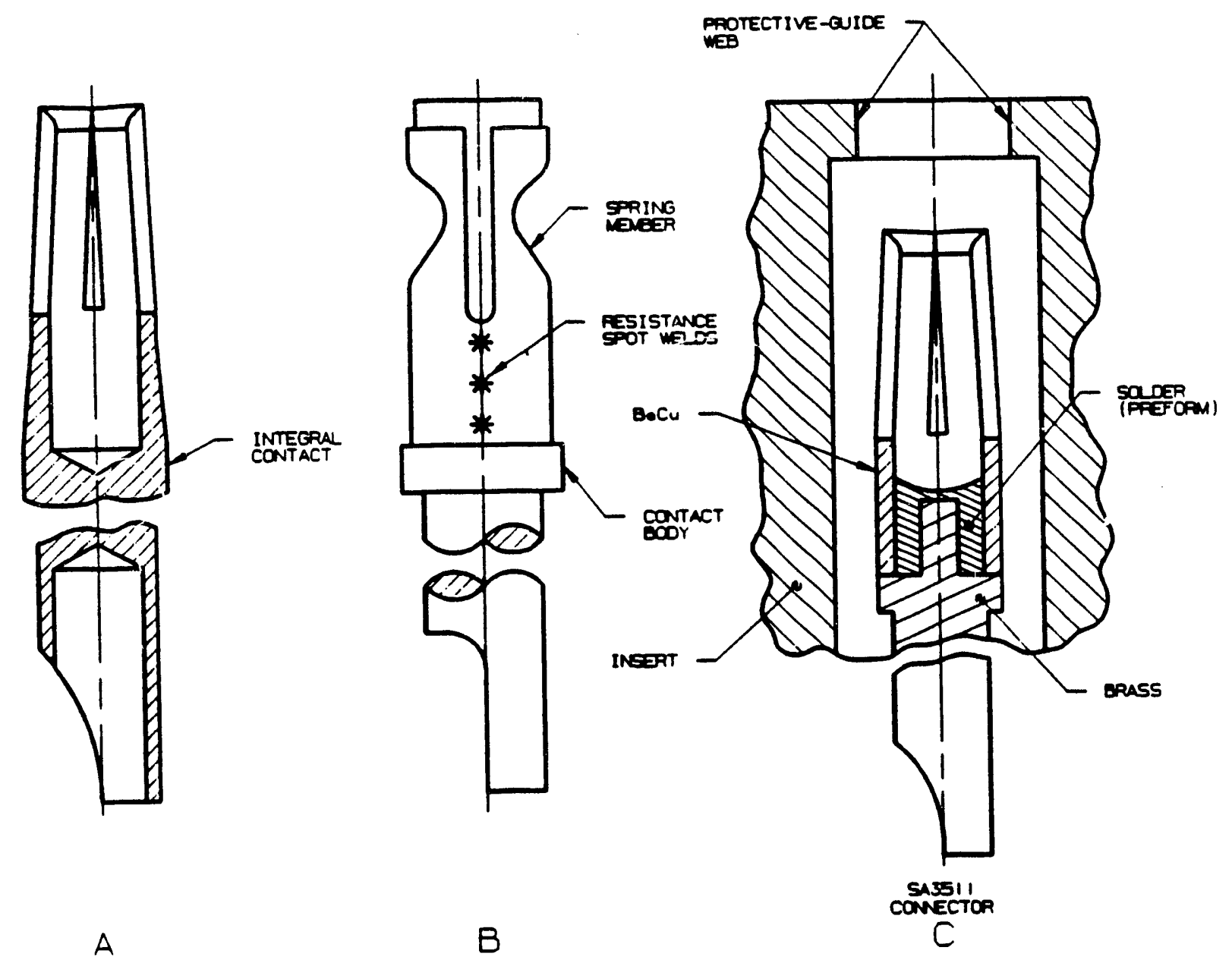

FIG. 10 


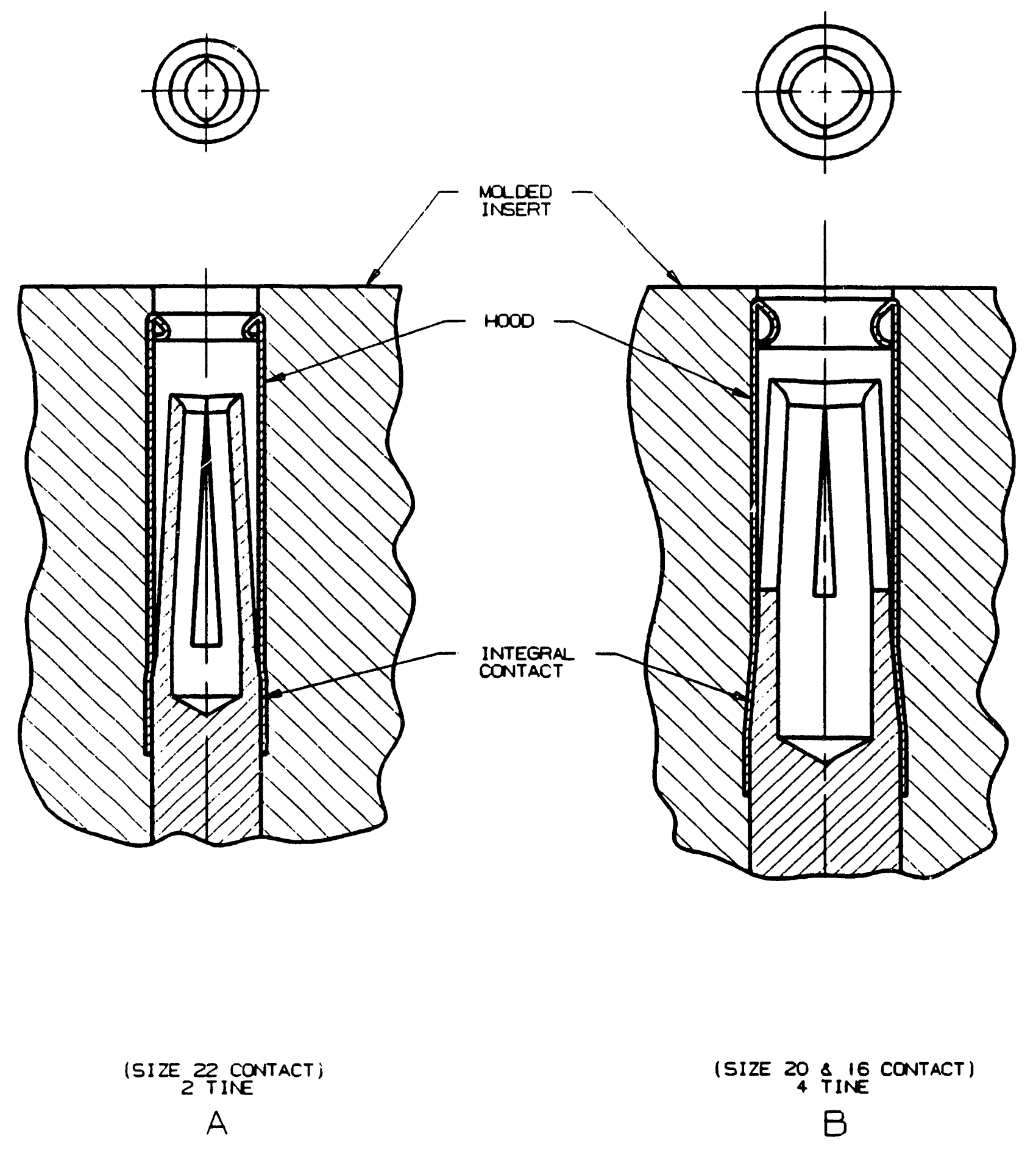

FIG. I I 

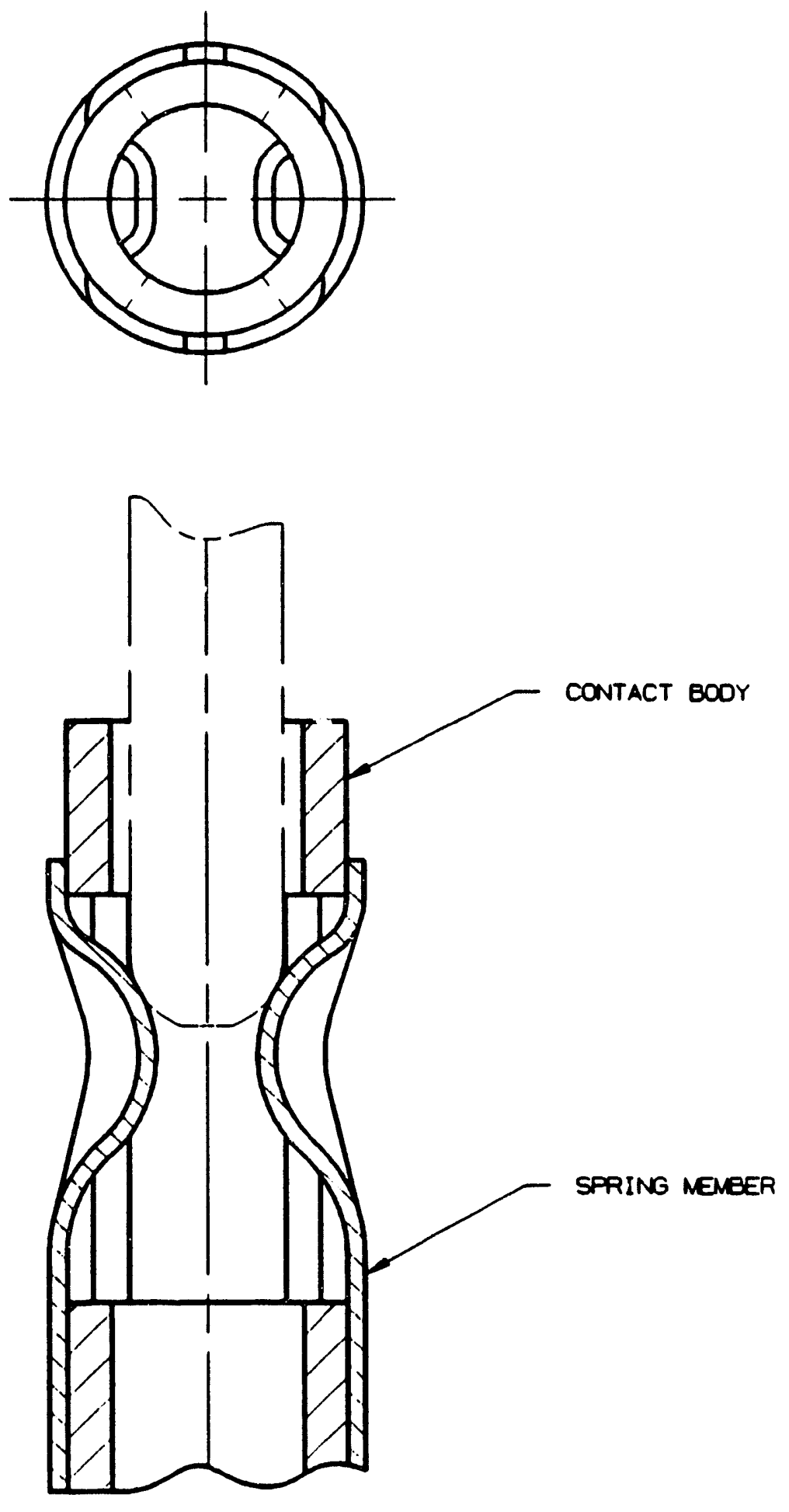

(SIZE 22 CONTACT)
FIG. 12 


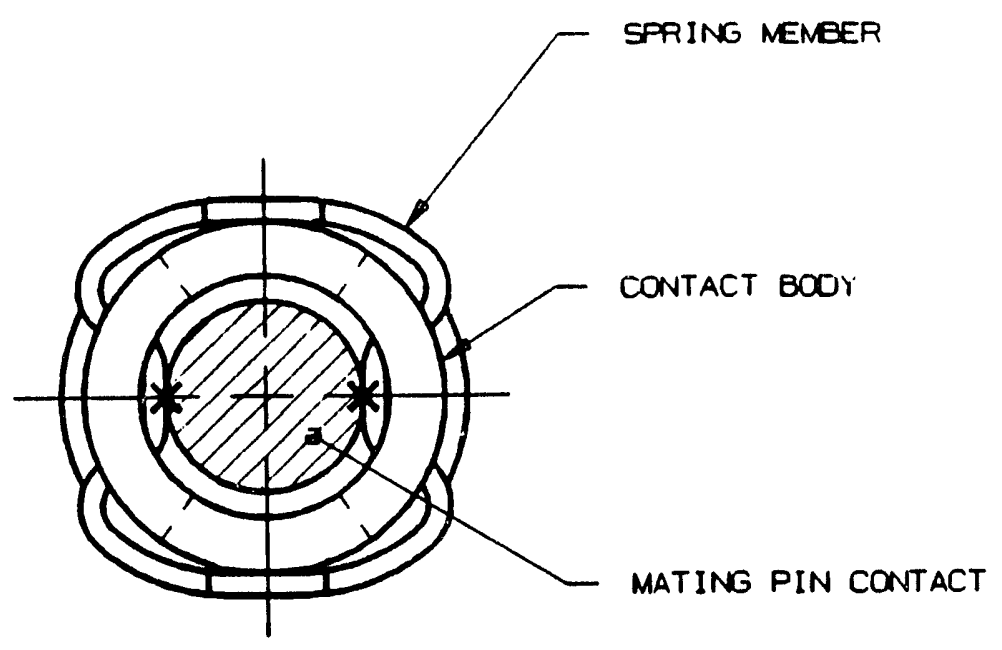

A

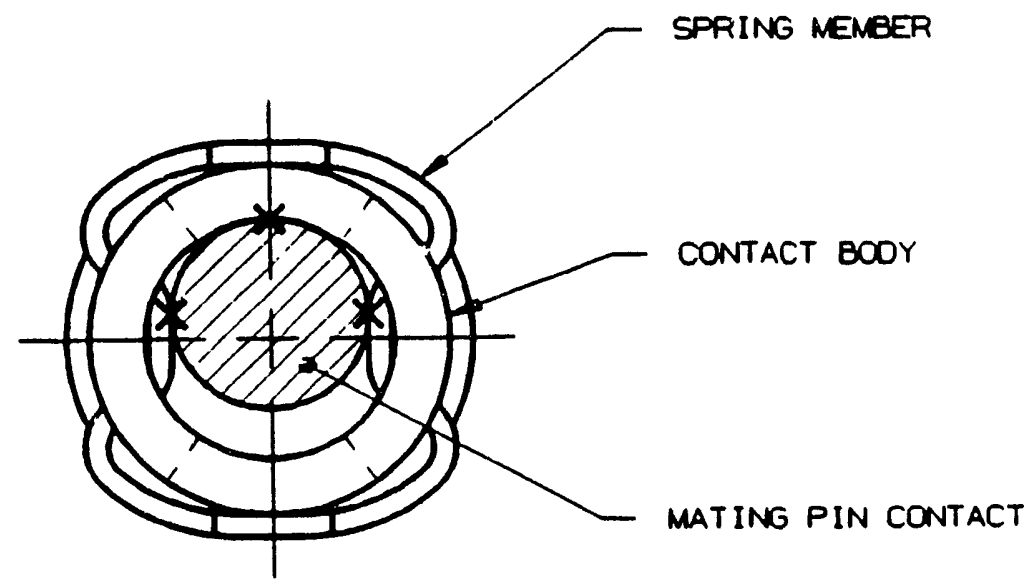

B

$X$ - SIGNIFIES POINT/LINE OF CONTACT

FIG. 13 
DISTRIBUTION:

$\begin{array}{rll}1 & 2500 & \text { G. N. Beeler } \\ 1 & 2550 & \text { D. W. Doak } \\ 1 & 2551 & \text { D. E. Carnicom } \\ 25 & 2551 & \text { J. R. F. Baca } \\ 1 & 2551 & \text { R. D. Holt } \\ 1 & 2554 & \text { T. R. Perea } \\ 1 & 2850 & \text { T. C. Cannon }\end{array}$

$1 \quad 2851$

$1 \quad 8523-2$

$5 \quad 3141$

$8 \quad 3145$

$3 \quad 3151$

L. K. Grube Central Technical Files

S. A. Landenberger Document Processing For DOE/OSTI

G. C. Claycomb 

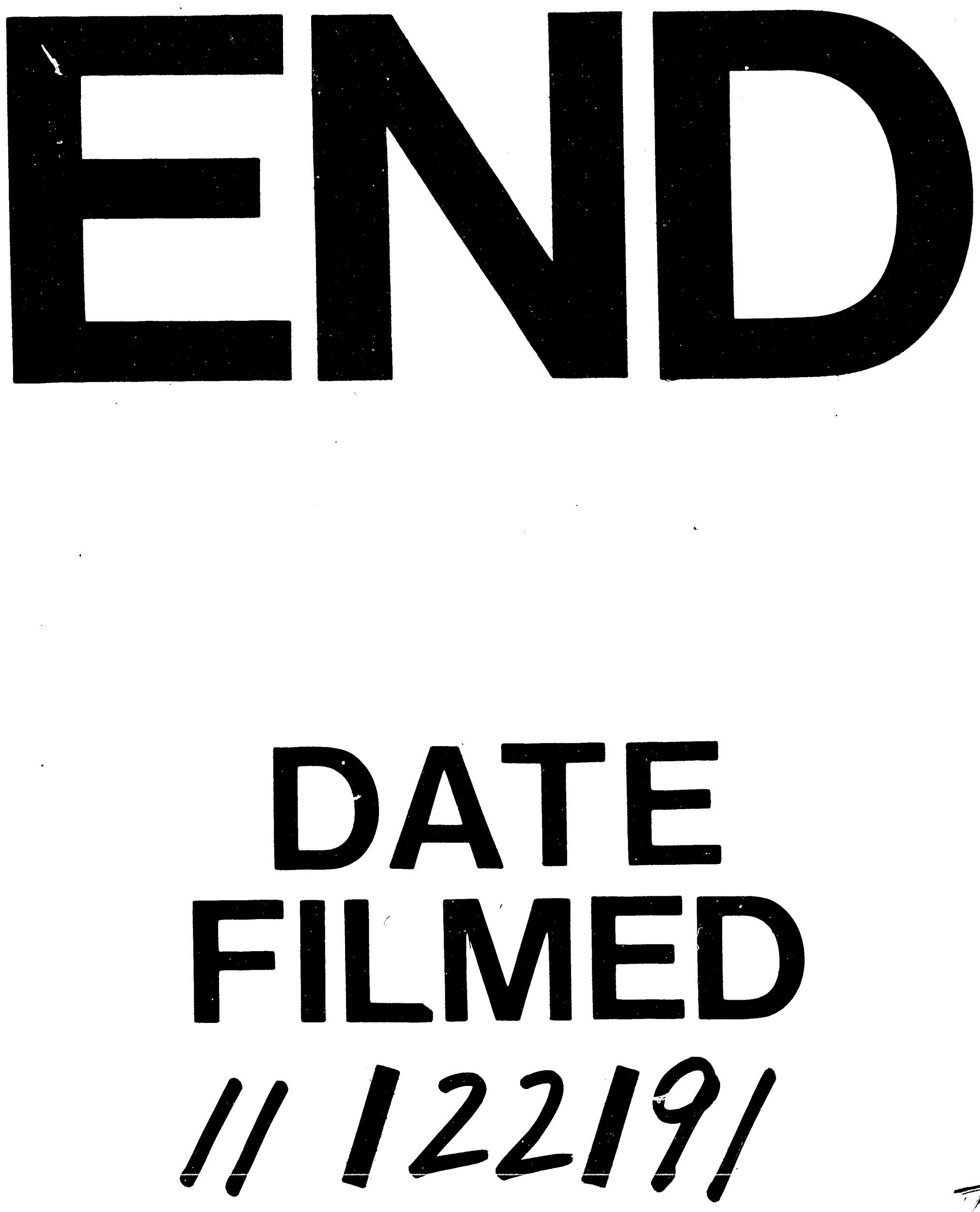
